\title{
Toward Understanding Molecular Mechanisms of Abiotic Stress Responses in Rice
}

\author{
Ji-Ping Gao $\cdot$ Dai-Yin Chao $\cdot$ Hong-Xuan Lin
}

Received: 28 April 2008 / Accepted: 3 July 2008 / Published online: 15 August 2008

(C) Springer Science + Business Media, LLC 2008

\begin{abstract}
Plants have evolved delicate mechanisms to cope with environmental stress. Following exposure to environmental stimuli, extracellular signals are perceived and transmitted through signal transduction cascades. Upon receipt and transmission of the signals, a number of stressrelated genes are induced, leading to stress adaptation in plant cells. Rice, which is a critical food grain for a large portion of the world's population, is frequently impacted by several abiotic stressors, the most important of which are drought, salinity, and cold. Exposure to environmental conditions outside of acceptable tolerance ranges can negatively affect rice growth and production. In this paper, a review of rice responses to abiotic stress is presented, with particular attention to the genes and pathways related to environmental stress tolerance. It is apparent that, while progress has been made in identifying genes involved in stress adaptation, many questions remain. Understanding the mechanisms of stress response in rice is important for all research designed to develop new rice varieties with improved tolerance.
\end{abstract}

J.-P. Gao $\cdot$ H.-X. Lin $(\bowtie)$

National Key Laboratory of Plant Molecular Genetics,

Shanghai Institute of Plant Physiology and Ecology,

Shanghai Institutes for Biological Sciences,

Chinese Academy of Sciences,

300 Fenglin Road,

Shanghai 200032, China

e-mail: hxlin@sibs.ac.cn

D.-Y. Chao

Department of Horticulture and Landscape Architecture,

Purdue University,

West Lafayette, IN 47907, USA
Keywords Abiotic stress · Rice · Signal perception and transduction · Transcription factor $\cdot$ Stress tolerance

Plant growth and productivity can be adversely affected by abiotic stress. Plants are exposed to any number of potentially adverse environmental conditions such as water deficit, high salinity, extreme temperature, and submergence. In response, plants have evolved delicate mechanisms, from the molecular to the physiological level, to adapt to stressful environments.

Rice is the staple food for more than half of the world's population. Evolved in a semi-aquatic, low-radiation habitat, rice exhibits distinct tolerance and susceptibilities to abiotic stresses among domesticated cereal crops [92]. Rice thrives in waterlogged soil and can tolerate submergence at levels that would kill other crops, and is moderately tolerant of salinity and soil acidity but is highly sensitive to drought and cold [92]. Cultivated over a broad region between $45^{\circ}$ north and south latitudes, rice plants are faced with low temperature in temperate regions, submergence in tropical regions, water deficit in humid tropics, and other stressors [109].

Arabidopsis is a good model in plant molecular biology and genetics research, and the majority of studies examining the impacts of abiotic stress have employed this plant [37, 85, 165, 183, 193]. The signaling pathways and regulatory network in Arabidopsis have been well characterized and well reviewed. Although progresses were also made on rice, reviews were less focused on this most important crop because of little functional genes characterized. Recent years, multiple genes contributing to abiotic stress responses in rice were identified by using genetics, reverse genetics, and molecular biology method. Here, we 
present a summary to display those progresses so as to better understand genetics and molecular mechanisms of rice response to abiotic stress.

\section{Signal perception}

Signal perception is the first step of plant response to environmental stress. A stress sensor can detect environmental variables and specifically transmit the initial stress signals to cellular targets. Some of the two-component histidine kinases (HK) function as stress sensors in bacteria and yeast. For example, the cyanobacterium Hik33 [166] and the Bacillus subilis DesK [6] are thermosensors that induce gene expression in response to low temperature. The Saccharomyces cerevisiae histidine kinase SLN1 is an osmosensor that activates the HOG1 mitogen-activated protien kinase (MAPK) pathway [110]. In the cyanobacterium Synechocystis, at least five HKs are involved in the perception of osmotic stress [127].

Each environmental stimulus provides plant cells with specific yet related information. Given a large number of potential stimuli, it is possible that plants may monitor the unique attribute of stress signals through different kinds of sensors [183]. To date, most of the stress sensors remain unidentified. Urao et al. [175] reported that the temperaturesensitive osmosensing-defective $\sin 1$ yeast mutant, $\sin 1$ - $t$, is lethal because the HOG1 MAPK cascade is constitutively activated at $37^{\circ} \mathrm{C}$ and Arabidopsis histidine kinase AHK1/ ATHK1 can nullify this mutation. Moreover, expression of $A H K 1 / A T H K 1$ in the yeast double mutant $\sin 1 \Delta \operatorname{shol} \Delta$, which lacks two osmosensors, activates the HOG1 pathway and confers high-osmolarity tolerance to the double mutant [175]. These results suggest that Arabidopsis AHK1/ ATHK1 can act as an osmosensor in yeast. Microarray analysis reveals that AHK1/ATHK1 functions upstream of several stress-responsive transcription factors, such as AREB1, ANAC, and DREB2A, and is a positive regulator of drought and salt stress responses through both abscisic acid (ABA)-dependent and ABA-independent signaling pathways [171]. In Arabidopsis, four of six nonethylene receptor histidine kinases, AHK1/ATHK1, AHK2, AHK3, and $\mathrm{AHK} 4 / \mathrm{CRE} 1$, are stress-responsive. However, unlike AHK1/ATHK1, AHK2, AHK3, and AHK4/CRE1 are negative regulators in ABA signaling, and $\mathrm{AHK} 2$ and AHK3 are negative regulators of osmotic stress responses [171]. AHK2, AHK3, and AHK4/CRE1 also function in cytokinin signaling $[54,122]$.

The two-component system, which typically contains two conserved proteins - a histidine protein kinase and a response regulator (RR) protein-plays an important role in the perception and integration of various extracellular and intracellular signals in prokaryotes, lower eukaryotes, and plants [14, 160, 173]. When activated by environmental stimuli, the histidine kinase autophosphorylates the conserved histidine residue within its transmitter domain. The phosphoryl group is subsequently transferred to an aspartate residue in the response regulator protein, resulting in a conformational change that activates a downstream signaling cascade [160]. The Arabidopsis RRs are classified into two distinct subgroups, type A RRs and type B RRs. Type B RRs, including 11 members, have a phosphorylatable receiver domain at their $\mathrm{N}$ terminus and a GARP DNAbinding domain in the middle, and function as DNAbinding transcriptional factors $[63,67,146]$. The type A RRs, including ten members, contain only the receiver domain with no DNA-binding domain [67, 68, 80]. Results from overexpression and mutant plants reveal that type A RRs are negative regulators of cytokinin signaling, while type B RRs are positive regulators [63, 80, 146]. But their roles in abiotic stress signaling remain unknown.

There are at least 14 histidine kinase genes, 15 type A RR genes, and seven type B RR genes identified in rice genome [30, 71, 73, 128], while most of them have not been intensively studied. As a result of alternative splicing, 14 genes encode 22 putative histidine kinases in Oryza sativa ssp. japonica, including at least seven members of the OsHK family that demonstrate a close relationship with AHK1/ATHK1 [128]. The induction of OsRR6 in response to salinity, dehydration, and low temperature indicates its role in both abiotic stress and cytokinin signaling [73]. In rice, the best studied two-component system protein is Early heading date 1 (Ehd1), a type B RR. Edh1 promotes flowering by inducing FT-like gene expression under shortday conditions, indicating that the two-component system is involved in photoperiodic flowering pathway in rice [28]. Two-component systems are also thought to be involved in sensing abiotic stress in rice, although their biological roles are not well understood.

\section{Signal transduction}

Once an extracellular stimulus is perceived, secondmessenger molecules, e.g., $\mathrm{Ca}^{2+}$, inositol phosphates, and reactive oxygen species (ROS), are immediately generated. Second messengers subsequently activate a downstream signal cascade that phosphorylates transcription factors that regulate the expression of a set of genes or proteins involved in stress adaptation [183]. Signaling can also bypass second messengers in the early signaling steps [183]. Phosphorylation by protein kinases is the most common and important regulatory mechanism in signal transduction. CBL-CIPK, CDPK, and MAPK pathways have been identified as being involved in plant stress signaling [105, 106, 169]. 


\section{CBL-CIPK pathway}

In plant cells, the concentration of cytosolic free $\mathrm{Ca}^{2+}$ rises transiently during early-stage stress response as a reaction to nearly all abiotic stresses $[84,150]$. The $\mathrm{Ca}^{2+}$ oscillation is generated through the opening of $\mathrm{Ca}^{2+}$-permeable channels that allow the downhill flow of $\mathrm{Ca}^{2+}$ from a compartment in which the ion is present at relatively high electrochemical potential to one in which $\mathrm{Ca}^{2+}$ is at lower potential (reviewed by [151]). The intracellular increase in calcium, due either to an influx from external sources or release from internal stores [47, 84], is perceived by various calcium-binding proteins, such as calcineurin B-like protein (CBL), and $\mathrm{Ca}^{2+}$-dependent protein kinase (CDPK) [105, 106, 151].

In Arabidopsis, the $\mathrm{Ca}^{2+}$ oscillation elicited during salt stress can be perceived by a $\mathrm{Ca}^{2+}$ sensor, SOS3/CBL4. SOS3 is an EF-hand-type calcium-binding protein whose amino acid sequence shares significant similarities with the yeast calcineurin B subunit and animal neuronal calcium sensors [100]. Calcineurin is a heterodimer consisting of a catalytic subunit A and a regulatory subunit B. Loss-offunction mutations in the calcineurin $\mathrm{B}$ subunit cause increased sensitivity of yeast cells to $\mathrm{Na}^{+}$and $\mathrm{Li}^{+}[113$, 119]. Although SOS3 has a low affinity for binding $\mathrm{Ca}^{2+}$, calcium binding is essential for the dimerization of SOS3, which leads to a change in the global shape and surface properties of the protein that is of sufficient magnitude to transmit the salt stress-induced $\mathrm{Ca}^{2+}$ signal [69, 149].

In the presence of $\mathrm{Ca}^{2+}, \mathrm{SOS} 3$ interacts physically with the regulatory domain of a calcineurin B-like-interacting protein kinase (CIPK), SOS2/CIPK24 [51]. SOS2 encodes a serine/threonine protein kinase with an N-terminal catalytic domain that is very similar to those of the yeast SNF1 and mammalian AMPK kinase, and a C-terminal regulatory domain that is unique to the CIPK family kinases [101]. Under normal conditions, the regulatory domain interacts with the catalytic domain to inhibit kinase activity by blocking substrate access to the catalytic site [48]. The binding of SOS3 to SOS2, which is mediated by the 21 amino acid residue FISL motif in the SOS2 regulatory domain, releases the catalytic domain that subsequently activates the substrate phosphorylation activity of SOS2 [48]. SOS3 is myristoylated at its $\mathrm{N}$ terminus, and the myristoylation is important for recruiting SOS2 to the plasma membrane and for phosphorylation of the $\mathrm{Na}^{+} / \mathrm{H}^{+}$ antiporter SOS1 [69, 132, 154] (Fig. 1).

The SOS pathway is highly conserved in rice. Mimicking their Arabidopsis homologs, OsSOS3/OsCBL4, OsSOS2/ OsCIPK24, and OsSOS1 functionally reconstitute the SOS pathway in yeast mutants that lack endogenous $\mathrm{Na}^{+}$ transporters and impart $\mathrm{NaCl}$ tolerance to those mutants $[112,134]$. OsSOS3/OsCBL4 and OsSOS2/OsCIPK24 can

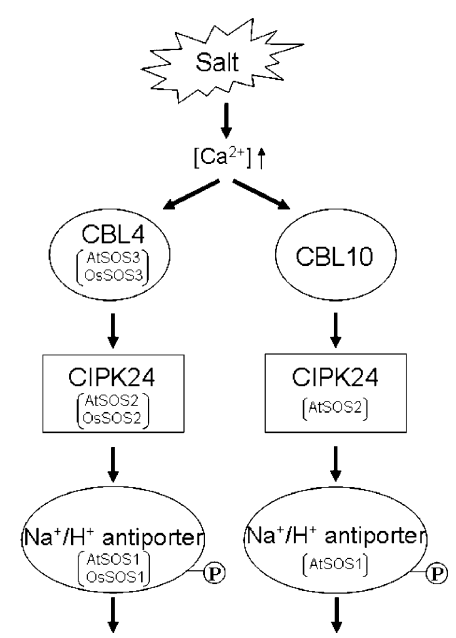

$\mathrm{Na}^{+}$efflux in root $\mathrm{Na}^{+}$efflux in shoot

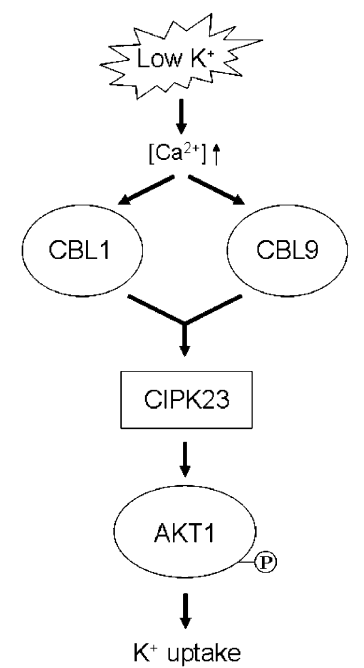

Fig. 1 CBL-CIPK pathway for maintaining ion homeostasis under high salinity and low- $\mathrm{K}^{+}$conditions. Salt and low- $\mathrm{K}^{+}$environmental conditions are perceived by unknown sensors, triggering different cytosolic $\mathrm{Ca}^{2+}$ signals. CBL4, CBL10, CBL1, and CBL9 perceive related $\mathrm{Ca}^{2+}$ signals; the first two proteins interact with CIPK24, while CBL1 and CBL9 interact with CIPK23. Plasma membrane $\mathrm{Na}^{+} / \mathrm{H}^{+}$ antiporter SOS1 is phosphorylated and activated by CBL4-CIPK24 in roots and by CBL10-CIPK24 in shoots, subsequently transporting $\mathrm{Na}^{+}$out of the cell. The CBL1/9-CIPK23 complex phosphorylates $\mathrm{K}^{+}$ channel AKT1, which enhances $\mathrm{K}^{+}$uptake under $\mathrm{K}^{+}$deficient conditions. Only CBL4-CIPK24 pathway has been confirmed in rice. At, Arabidopsis; Os, rice.

be exchanged with their Arabidopsis counterparts to form heterologous protein kinase modules that activate both OsSOS1 and AtSOS1, and suppress the salt sensitivity of sos 3 and sos 2 Arabidopsis mutants, respectively [112]. The conservation among the SOS proteins from Arabidopsis and rice implicates that the SOS machinery may also function in other cereals.

Studies have shown that there are at least ten CBLs and 25 CIPKs in Arabidopsis [105], and ten CBLs and 30 CIPKs in rice [88]. Because each CBL protein may interact with more than one CIPK protein and vice versa [88, 105], functional diversification of the CBL-CIPK pathways that are relevant for stress signaling deserve further study. Recent evidence has revealed SOS3-SOS2 complex functions in root tissues, whereas CBL10 responds to salinity by activating and recruiting SOS2 in the shoot [133]. Two independent studies have shown that the CBL1/9-CIPK23 pathway enhances $\mathrm{K}^{+}$uptake by activating $\mathrm{K}^{+}$channel AKT1 in Arabidopsis in response to $\mathrm{K}^{+}$-deficient conditions [96, 184].

Despite the data gathered by several recent investigations, the functional identification of all rice $\mathrm{CBL}$ proteins is still in its infancy, except for some reports on the functions of mouse calcineurin in rice and OsCBL2 in aleurone cells. The protein phosphatase 2B (PP2B) calcineurin plays a central role in the signaling pathway that 
regulates $\mathrm{Na}^{+}$and $\mathrm{K}^{+}$homeostasis [143]. Deletion of the Cterminal autoinhibitory domain from the mouse calcineurin A subunit constitutively activates phosphatase activity. Expression of this truncated calcineurin A subunit in rice enhances salt stress tolerance by limiting $\mathrm{Na}^{+}$accumulation in roots [107]. Among ten genes, only OsCBL2 is upregulated in aleurone by gibberellic acid (GA); other OsCBLs are not induced by GA and ABA in the aleurone layer or vegetative tissues [64]. OsCBL2 targets to the aleurone tonoplast and promotes vacuolation in aleurone cells through the GA-signaling pathway [64].

CIPKs have been identified as having a diverse role in different stress responses in rice. Analysis of the expression profile shows that drought, salinity, cold, polyethylene glycol (PEG), and ABA induce expression of 20 OsCIPK genes [180]. Most of the drought- or salt-inducible genes are also induced by treatment with $\mathrm{ABA}$ but not by cold [180]. Transcripts of OsCIPK12/OsPK7 increase during drought or exposure to PEG and ABA, regardless of light, nutrient, and cytokine status [124, 180]. OsCIPK3/OsCK1, whose expression is induced by cold, salt, light, sugar, cytokinin, and calcium, interacts with AtCBL3 through the C-terminal regulatory region [82]. The truncated form of OsCIPK3/OsCK1 (without the C-terminal) has normal substrate phosphorylation activity but decreased autophosphorylation activity [82]. Overexpression of OsCIPK3, OsCIPK12, and OsCIPK15 in rice improves cold, drought, and salt tolerance, respectively [180].

\section{CDPK pathway}

Another well-studied class of calcium-binding protein in the $\mathrm{Ca}^{2+}$ signaling pathway is CDPK. CDPKs, which contain a calmodulin-like domain to which $\mathrm{Ca}^{2+}$ can be bound and a Ser/Thr kinase domain, can sense and transmit calcium signals by a single protein $[52,138,151]$. CDPKs constitute one of the largest subfamilies of plant-specific protein kinase [106]. Availability of the whole genome sequence allows identification of 34 and 31 CDPK genes in Arabidopsis [23, 58] and in the rice genome [9, 135], respectively.

Expression analyses of different plant $C D P K s$ provide evidence for their diverse functions in plant signal transduction [106]. Twelve $O S C D P K$ genes exhibit cultivarand tissue-specific expression [177], and 31 OsCDPK genes were found to express during the vegetative, panicle, and seed developmental stages [135]. Expression of OsCPK9 is increased in plants infected with rice blast [9]. $C D P K S$ are also involved in a plant's response to abiotic stresses. Seven OsCDPK genes have been found to accumulate differentially during cold, salt, and desiccation stress [135]. OsCDPK7 [19, 145], AtCDPK1 and AtCDPK2 [174] are induced by salt; OsCDPK7 [145], OsCDPK13
[1], and $Z m C D P K 1$ [12] are induced by cold; $O s C D P K 2$ [16], CpCPK1 [32], ZmCDPK7, and ZmCDPK9 [144] are down-regulated by light; $O s C D P K 2$ is down-regulated by anoxic treatment [16].

Functional analyses using transgenic plants have revealed the biological function of some $C D P K$ genes in higher plants. The $N t C D P K 2$-silenced tobacco plants show a reduced and delayed hypersensitive response (HR) to the fungal Avr9 elicitor [139]. Overexpression of cold- and salt-inducible $O s C D P K 7$ results in enhanced tolerance to cold, salt, and drought, suggesting a function for this gene in the corresponding signaling pathways [145]. At the transcript level, OsCDPK13 responds to various abiotic stresses as well as to hormone levels. OsCDPK13 gene expression and protein accumulation are enhanced in response to cold and $\mathrm{GA}_{3}$ treatment but suppressed under drought, salt and $\mathrm{ABA}$ exposure, and brassinolide treatment [1]. Sense $O s C D P K 13$ transgenic lines are resistant to cold stress; antisense lines show the dwarf phenotype, which suggest that OsCDPK13 has a role in both abiotic stress tolerance and leaf sheath elongation [1].

The activation of CDPKs is dependent upon $\mathrm{Ca}^{2+}$ binding. Activated CDPKs relay signals through phosphorylation of specific substrates, many of which have been described [52]. Sucrose synthase is a substrate for CDPK in maize [62], soybean [189], and rice [10]. An OsCDPK

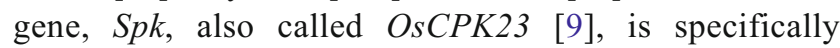
expressed in developing rice seeds [78]. SPK phosphorylates a Ser residue in sucrose synthase, which catalyzes the initial step in starch biosynthesis from sucrose [10]. Phosphorylation is important for sucrose synthase activity in the degradation of sucrose. Transgenic plants containing the antisense $S p k$ gene are defective in starch accumulation, producing a water-rich seed rather than one containing starch granules [10]. In the common ice plant, Mesembryanthemum crystallinum, McCDPK1 phosphorylates CSP1, a pseudo-response regulator-like protein, in vitro in a $\mathrm{Ca}^{2+}$-dependent manner [129]. McCDPK1 colocates with CSP1 in the nucleus under salt stress. However, while McCDPK1 is induced by salt and drought, CSP1 is not [129]. Several OsCDPKs show a response to abiotic stress, but information regarding the targets of each individual gene is limited.

\section{MAPK pathway}

Mitogen-activated protein kinase (MAPK) pathways are highly conserved among yeast, animals, and plants [179]. MAPK protein phosphorylation cascades are typically comprised of three sequentially acting protein kinases, a MAPK kinase kinase (MAPKKK), a MAPK kinase (MAPKK), and a MAPK. These three-component modules link a variety of extracellular stimuli to cellular and nuclear 
response. In plants, MAPK cascades play important roles in responding to hormones, cell division, development, and biotic and abiotic stresses [75, 169].

The Arabidopsis genome encodes 60 MAPKKKs, ten MAPKKs, and 20 MAPKs [111]. Based on yeast twohybrid analysis and functional complementation tests of yeast mutants related to the MAPK cascade, a putative MAPK cascade, MEKK1-MEK1/MKK2-MPK4, has been identified [65, 117]. Genetic and biochemical evidence indicate that MEKK1-MKK2-MPK4/MPK6 mediate cold and salt stress signaling in Arabidopsis [167] (Fig. 2). Transcription of MAPK kinase kinase MEKK1 increases markedly in response to cold, salt, and drought stress [116]. MEKK1 specifically phosphorylates and activates MAPK kinase MKK2; MKK2 then directly targets and activates the downstream MAPK MPK4 and MPK6 in vivo [167]. MKK2-overexpressing plants exhibit constitutive MPK4 and MPK6 activity, and improved cold and salt tolerance [167]. Another Arabidopsis MAPK cascade composed of MEKK1-MKK4/MKK5-MPK3/MPK6 functions in innate immunity [8], indicating the existence of biotic and abiotic stress-signaling cross-talk among MAPK modules.

Although little is known about the composition and function of classical three-component modules in rice, several MAPKs implicated in abiotic stress signal transduction have been identified [5]. Salt, cold, and sugar starvation induce the expression of OSMAPK4, which is differentially expressed at different development stages [35]. A MAPK gene, OsMAP1 (also named OsMAPK5, OsMSRMK2, OsMAPK2, and OsBIMK1), is induced by multiple biotic and abiotic stresses such as pathogen infection, low temperature, salinity, drought, and $\mathrm{ABA}[4,61$,
159, 178, 182]. OsMAP1 can inversely modulate abiotic stress tolerance and broad-spectrum disease resistance. Plants overexpressing OsMAP1 exhibit increased kinase activity and elevated tolerance to cold, salt, and drought. Interestingly, rice lines that suppress OsMAP1 show reduced resistance to abiotic stress but significantly increased resistance to fungal and bacterial pathogens [182].

Only a few upstream components, MAPKKK, and MAPKK, have been investigated in rice. Expression analysis reveals that MAPKKK OsEDR1, an ortholog of Arabidopsis AtEDR1, is probably associated with development and the defense/stress response [81]. The expression pattern of MAPK kinase OSMEK1 is similar to that of OsMAP1 under abiotic stress [178]. Both OsMEK1 and OsMAP1 messenger RNA levels are induced by treatment at a moderately low temperature $\left(12^{\circ} \mathrm{C}\right)$ but not at $4^{\circ} \mathrm{C}$. Two-hybrid analysis reveals that OsMEK1 interacts with OsMAP1. The OsMEK1-OsMAP1 pathway, therefore, may be involved in moderately low-temperature signaling in rice [178].

Heavy metals such as cadmium, copper, and zinc induce the activation of several OsMAPKs [98, 187, 188]. A common response to abiotic stress is the production and accumulation of reactive oxygen species in plant cells. In Arabidopsis, hydrogen peroxide $\left(\mathrm{H}_{2} \mathrm{O}_{2}\right)$ can specifically induce a MAPKKK, ANP1, which leads to the activation of AtMPK3 and AtMPK6 [89]. In rice roots, $\mathrm{Zn}$-induced activation of $40-$ and $42-\mathrm{kDa}$ MAPK was suppressed by treatment with a ROS scavenger, suggesting that second messenger ROS may mediate a Zn-triggered MAPK pathway [98]. However, information regarding the downstream factors of MAPK pathway is still limited in rice.
Fig. 2 Schematic illustration of MAPK pathways for abiotic stress signaling in Arabidopsis and rice. The general tiers of the MAPK signal pathway are shown in the far left column. The arrows indicate activation of downstream components. A question mark indicates unidentified components.

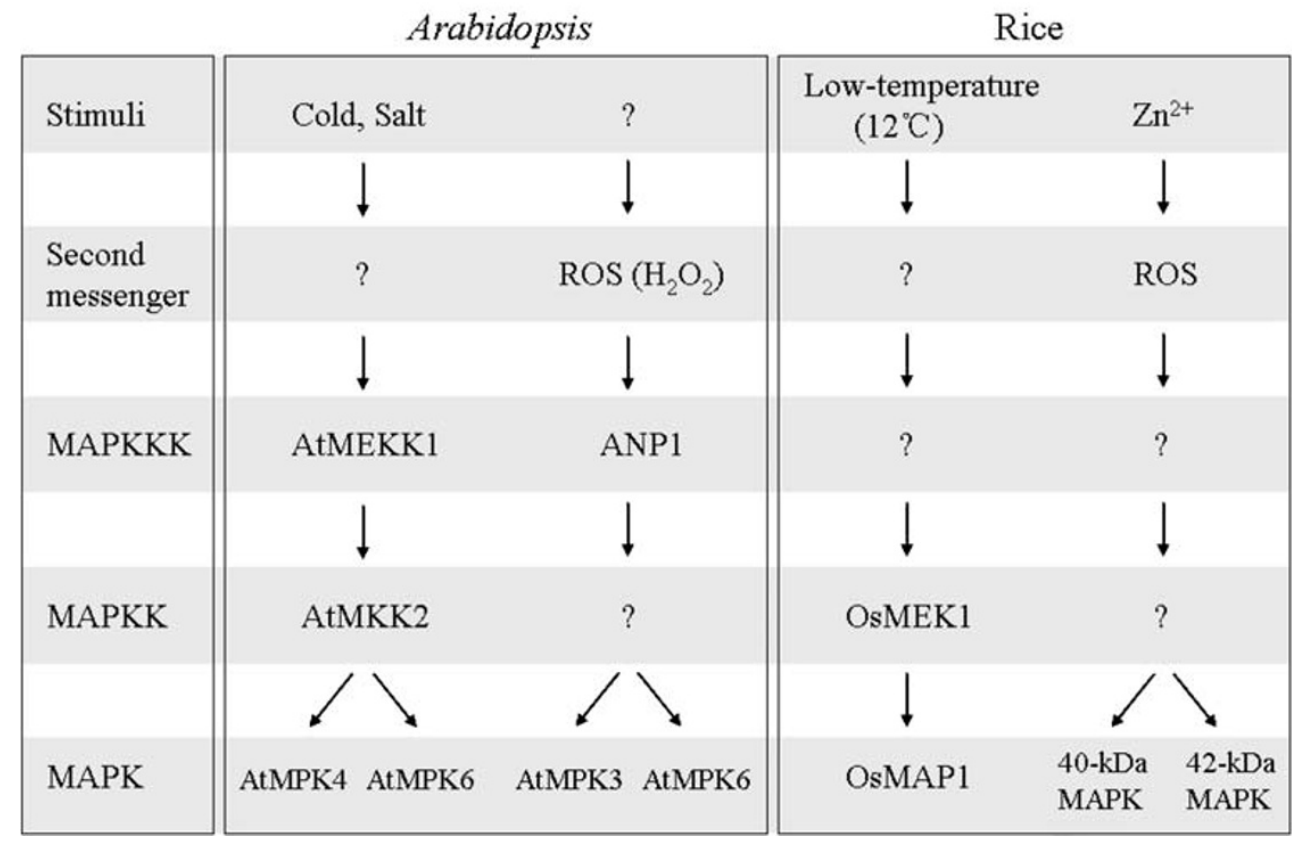


The duration and magnitude of MAPK activation may be regulated at many locations along the signaling pathway, but a major point occurs at the MAPK level [79]. Dual-specificity MAPK phosphatases (MKPs) are negative-feedback regulators of the MAPK cascade that dephosphorylate both threonine and tyrosine residues and inactivate MAPKs. OsMKP1 has been shown to be a negative regulator of the wound response in rice. Among five putative rice $M P K s$, only the expression of OsMPK1 is rapidly induced by wounding [77]. In contrast to the normal phenotype of the Arabidopsis atmkpl mutant, osmkp1 loss-of-function plants show a semi-dwarf phenotype. In osmkpl mutants, both the activities of two stress-responsive MAPKs and the expression of wounding-inducible genes are elevated, resulting in constitutive activation of the wound response [77].

\section{ABA signaling}

ABA is the most important phytohormone for plant coping with abiotic stress, especially drought and salt stresses. There are at least two effects of ABA on plant response to abiotic stress: inducing stomata closure and regulating expression of a big part of abiotic stress responsive genes. Identification of $\mathrm{ABA}$ receptors is a breakthrough for $\mathrm{ABA}$ signaling. So far, three ABA receptors were reported [103, $136,153]$, and a $\mathrm{G}$ protein coupled-receptor was proven to mediate both effects above of ABA [103]. As similar proteins have been found in rice genome (unpublished data), similar mechanisms of ABA perception may also exist in rice.

In addition to the perception of ABA signaling, ABA signal transduction was also better understood because of characterization of some sucrose non-fermenting 1-related protein kinase 2 (SnRK2s). Recent studies in both Arabidopsis and rice have shown that SnRK2s can be activated by both ABA and abiotic stress [15, 18, 36, 86, 87]. The activated SnRK2s phosphorylate and activate $\mathrm{AREB} / \mathrm{ABF} / \mathrm{ABI}$, and subsequently activate expression of $\mathrm{AREB} / \mathrm{ABF} / \mathrm{ABI} 5$ target genes $[15,18,36,86]$. It is known that ABA-mediated stomata closure involves reactive oxygen (for example, $\mathrm{H}_{2} \mathrm{O}_{2}$ ), but the detailed process is till unknown. However, an ABA-induced transcription factor, SNAC1 (described below), may be an important downstream factor for the process, given $S N A C 1$ is dominantly expressed in the stoma and overexpression of SNAC1 leads to stomata closure [60].

\section{Transcriptional regulation network}

It has been estimated that about $10 \%$ of the yeast genes are transcriptically affected by salt stress [192]. Although the proportion of affected genes in higher plants seems lower, based on published expression profile data, the actual number should be even higher than that in yeast, considering that higher plants are composed of several highly differentiated tissues and cells. For example, the abiotic stress-affected genes in roots and shoots, and in guard cells and mesophyll cells are quite different [19, 90, 95]. The transcriptional regulation networks of higher plants, therefore, are likely to be much more complex. To date, multiple regulons involved in reprogramming of abiotic stress have been identified (Fig. 3). Although current data are inadequate to provide a clear picture of the functional stress response pathways in higher plants, ongoing progress will continue to expand our understanding of the complex mechanisms that are involved.

\section{CBF/DREB pathway}

The CBF/DREB pathway was one of the first identified through transcriptional regulation research of abiotic stress and, now, is the best documented [25, 26, 170, 186, 191]. $\mathrm{CBF} / \mathrm{DREB}$ is an ERF/AP2 family transcription factor and specifically binds CRT/DRE elements and activates responding genes with those elements [186]. There are multiple CBFs/DREBs in Arabidopsis that respond to different abiotic stresses [50, 102, 161, 186]. Among these, $D R E B 1 A / C B F 3, D R E B 1 B / C B F 1$, and $D R E B 1 C / C B F 2$ are specifically induced by cold, and $D R E B 2 A$ and $C B F 4$ mainly respond to salt and drought stress [50, 102, 161, 186].

The CBF/DREB pathway is vital in the abiotic stress response in plants. Overexpression of $\mathrm{CBF} / \mathrm{DREBs}$ or modified CBFs/DREBs in Arabidopsis or rice significantly enhanced their tolerance of abiotic stress [31, 70, 72, 102, 148]. These data also suggested that the CBF/DREB pathway is conserved in rice. Actually, five DREB homologs, OsDREB1A, OsDREB1B, OsDREB1C, OsDREB1D, and OsDREB2A, were identified in rice [31]. The expression patterns of these genes are similar to their homologs in Arabidopsis, that is, OsDREB $1 A$ and $O s D R E B 1 B$ are induced by cold and $O S D R E B 2 A$ is induced by salt and drought [31]. Overexpression of these genes also enhanced the tolerance of Arabidopsis and rice to abiotic stress [31, 70, 123]. There are, however, some differences between OsDREBs and their orthologs in Arabidopsis. OsDREBs specifically bind the DRE/CRT core sequence GCCGAC [31], while AtDREBs show equal affinity to GCCGAC and ACCGAC [102, 161]. This implies that the abiotic stress tolerance mechanisms continued to evolve after the divergence of dicotyledons and monocotyledons.

Recent researches have been successful in identifying the upstream factors of this pathway by screening EMSmutated Arabidopsis with the CRT/DRE element or $C B F$ / $D R E B$ promoter-driven reporter gene [25, 26, 191]. ICE is 
Fig. 3 Transcriptional regulation network under abiotic stress in rice. At least three transcriptional pathways, involving three kinds of transcription factors $(T F s)$ as indicated, have been identified in rice. Based on knowledge from rice and/or Arabidopsis, upstream components and target genes or outputs of these TFs are also displayed. Black solid arrows indicate pathways with evidence from rice, grey solid arrows indicate pathway with evidence from Arabidopsis, and broken arrows indicate pathways without direct evidence. NBS NACbinding site.

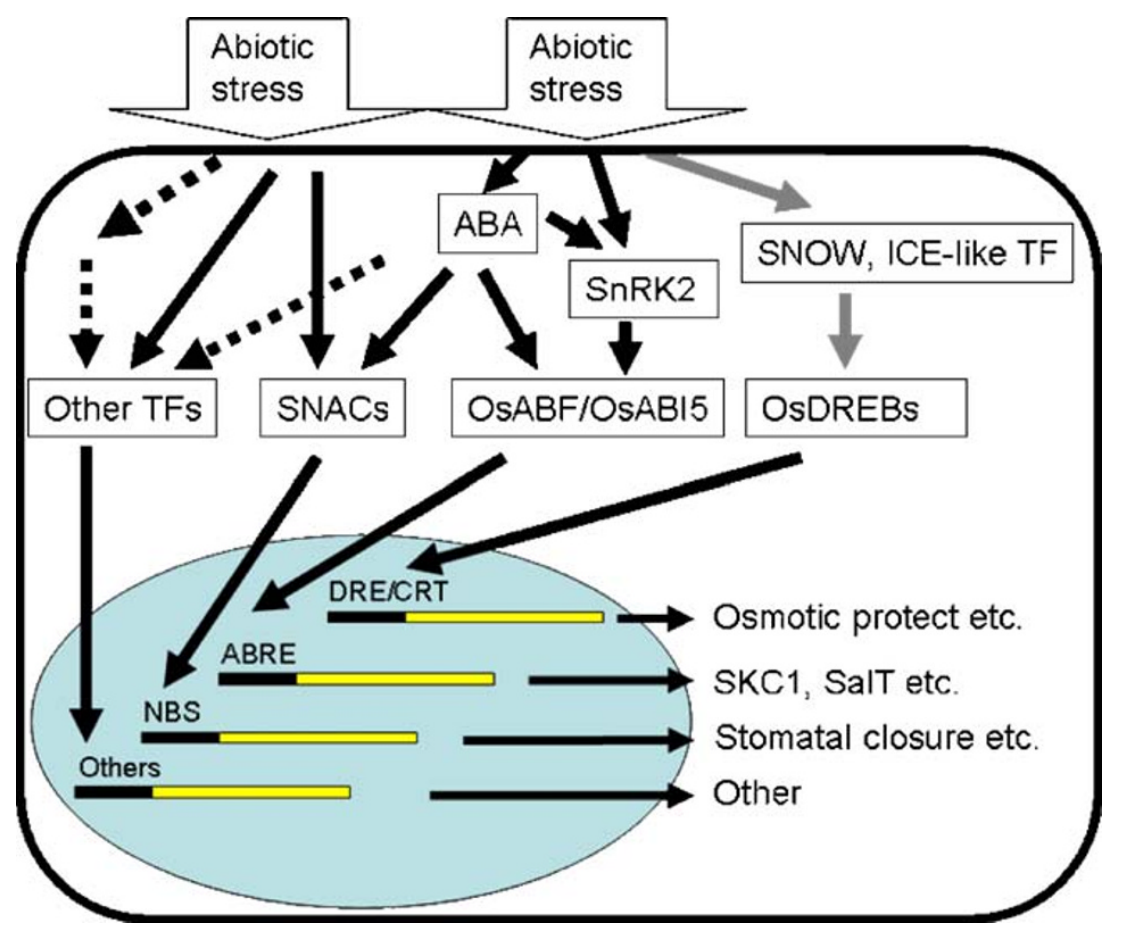

the first trans-factor that was found to bind the ICE box in the promoter of $C B F / D R E B$ and control the expression of $\mathrm{CBFs} / \mathrm{DREBs}[27,94]$. It also can control the expression of other transcription factors involved in plant stress tolerance, suggesting a key role in transcriptome reprogramming under environmental stress [94]. Another protein, named SNOW, has also been tentatively identified as being involved in transcription control of CBF/DREB by serving as an ICE partner (unpublished, http://www.faculty.ucr.edu/ $\sim \mathrm{jkzhu} /$ ). Other Arabidopsis factors, such as HOS1 and SIZ1, that control ICE steady state by regulating its ubiquitination and sumolylation respectively were also identified $[29,115]$. In rice, some putative proteins show high similarities with ICE1, HOS1, and SIZ1 in sequences (unpublished data). Although their functions remain to be characterization, a similar pathway in rice is expected.

\section{AREB/ABF/ABI5/bZIP}

Abiotic stress-induced genes also can be induced by ABA. The cis-elments responding to ABA were identified as ABRE (ABA-responsive element) and MYBRS/MYCRS (MYB/MYC recognition sequence) [24, 156, 170]. The transcription factors binding these cis-elements are AREB/ $\mathrm{ABF} / \mathrm{ABI} 5$ [38, 172] and MYB/MYC [2, 3], respectively. $\mathrm{AREB} / \mathrm{ABF}$ is a bZIP-type transcription factor, which can bind the ABRE cis-element. ABI5, a mutation that leads to Arabidopsis plants that were insensitive to ABA, was also found to encode a bZIP transcription factor and belong to the $A R E B$ family [33]. Rice $A B I 5$, which was recently identified, is also transcriptically regulated by $\mathrm{ABA}$ and multiple abiotic stresses. Knockdown of OsABI5 enhanced salt tolerance in rice and affected expression of some saltstress-responsive genes (for example, SKC1 and SalT), indicating that the ABRE/ABF/ABI5 pathway also exists in rice [194].

\section{NACs}

Some dehydration-induced genes in Arabidopsis, ERD1, for example, have no DRE/CRT elements in their promoter region and yet are regulated like those that do contain DRE/ CRT elements [83, 120, 158]. Studies have demonstrated that a MYC-like site, NACRS, and its binding factorsNAC family transcription factors - are required for induction of these genes [158].

There are also numerous genes that encode NAC transcription factors in the rice genome [126]. Some of them are also induced by abiotic stress $[19,59,60,121$, 125], suggesting that the NAC regulation pathway is conserved in rice. Overexpression of two rice $N A C$ genes, $S N A C 1$ and $S N A C 2$, significantly enhanced rice tolerance to abiotic stress, including cold, drought, and salt [59, 60]. $S N A C 1$ is dominatively expressed in rice guard cells, and its overexpression promoted stomatal closure [60]. It is believed, therefore, that SNAC1 functions in stoma movement under dehydration stress. Transcriptome analysis of overexpression lines of these two genes showed that their target genes are not rich with NACRS in the promoter regions $[59,60]$, suggesting that they are different from the 
Arabidopsis NACs that are involved in dehydration tolerance [158]. Furthermore, there are few of the SNAC1 and SNAC2 target genes, suggesting that multiple NAC pathways are associated with abiotic stress response.

\section{Other TFs}

Other kinds of transcription factors also play vital roles in transcriptional regulation during stress conditions, although little information is available about their upstream regulators or direct targets. It has been demonstrated that Sub1A-1, an ethylene-response-factor (ERF), is the major genetic determinant for submergence tolerance in rice [185]. Sub1A-1 finely modulates acclimation responses to sudden and total inundation to maintain the capacity of regrowth when water subsides. For example, Sub1A-1 inhibits leaf elongation by suppressing the expression of expansin-encoding genes and restrains carbohydrate consumption by reducing the expression of $\alpha$-amylose genes and sucrose synthase genes [39].

Although multiple cis-elements and trans-factors for transcriptional regulation under abiotic stress have been identified and characterized, a clear explanation of the complex transcription network and the huge number of abiotic stress responsive genes remains elusive. For example, it was found that only $12 \%$ of the cold responsive genes in Arabidopsis are regulated by CBF/DREB [34]. In addition, some of the CBF/DREB-regulating genes have no DRE/CRT element in their promoters [34]. It is very likely that these genes are controlled by CBF/DREBregulating transcriptional factors (e.g., RAP2.1) [34]. Chen et al. [22] used transcription factor microarray analysis to demonstrate that at least 30 transcription factors in Arabidopsis were induced by abiotic stress. A similar situation exists in rice. Microarray analysis revealed that transcription factor genes are rich within the group of the earliest salt-responsive genes [19]. Considering the spatial and temporal expression pattern of the abiotic stress responsive genes, it is highly likely that many transcription factors and regulatory pathways related to abiotic stress remain to be identified.

\section{Functional proteins}

Plant stress tolerance depends on the correct regulation of physiological mechanisms. This is achieved by multiple functional proteins participating in developmental, biosynthetic, and metabolic pathways. Based on changes at the transcript or/and activity level, functional proteins protect cells from stress by the removal of toxic elements, restoration of cellular homeostasis, and eventual recovery of normal growth patterns. For this review, we focused on enzymes associated with ROS scavenging and biosynthesis of compatible solutes and sodium transporters.

ROS scavenging system

ROS, including singlet oxygen $\left(\mathrm{O}_{2}{ }^{1}\right)$, superoxide radical $\left(\mathrm{O}_{2}{ }^{-}\right)$, hydrogen peroxide $\left(\mathrm{H}_{2} \mathrm{O}_{2}\right)$, and hydroxyl radical $\left(\mathrm{HO}^{-}\right)$, are generated during aerobic metabolism and abiotic stress conditions. They are capable of unrestricted oxidation of various cellular components and can lead to membrane lipid peroxidation, protein oxidation, and enzyme inhibition [114]. Plant cells remove excess ROS produced during stress conditions by enzymatic and non-enzymatic mechanisms.

ROS-scavenging enzymes include superoxide dismutase (SOD), ascorbate peroxidase (APX), glutathione peroxidase (GPX), and catalase [7]. APX and GPX are the most studied scavenging enzymes in rice [76, 97, 168]. They belong to the plant peroxidase superfamily and catalyse the conversion of $\mathrm{H}_{2} \mathrm{O}_{2}$ to $\mathrm{H}_{2} \mathrm{O}$. Because ROS also function as second messengers, their generation and removal are tightly regulated in different cellular components. There are eight APX enzymes in rice: two cytosolic (OsAPX1 and OsAPX2), two peroxisomal (OsAPX3 and OsAPX4), one mitochondrial (OsAPX6), and three chloroplastic isoforms (OsAPX5, OsAPX7, and OsAPX8) [168]. OsGPX1 and other plant GPX enzymes, on the other hand, are cytosolic [7, 76]. Under salt stress, OsAPX2, OsAPX7, and OsAPX8 show altered transcript levels [168], but only OsAPX8 is induced in roots [55]. $\mathrm{NaCl}, \mathrm{ABA}$, and $\mathrm{H}_{2} \mathrm{O}_{2}$ can enhance the expression of $O S A P X 8$ in rice roots, while the $\mathrm{NaCl}-$ induced expression of $O S A P X 8$ is mediated through the accumulation of ABA but not $\mathrm{H}_{2} \mathrm{O}_{2}$ [55]. Even isoforms with the same subcellular location may have distinct functions. Expression analysis reveals that $O S A P X 2$ is upregulated by salt [168]. Arabidopsis plants expressing OSAPX2 exhibit higher ROS-scavenging activity and salt tolerance than those expressing OsAPX1 [104].

Non-enzymatic antioxidants include the major cellular redox buffers ascorbate and glutathione, as well as carotenoids and tocopherol [7]. Alleviation of oxidative injury by the use of antioxidants can enhance plant resistance to abiotic stress. Guo et al. [49] found that feeding rice roots with L-ascorbic acid and its immediate precursor protected plants against oxidative damages, suggesting that manipulation of ascorbic acid biosynthesis could be a strategy for improving stress tolerance. During the antioxidation process, ascorbate itself is oxidized to dehydroascorbate; dehydroascorbate reductase (DHAR) rereduces the oxidized ascorbate. A high ratio of reduced to oxidized ascorbate is important for ROS-scavenging efficiency. Ushimaru et al. [176] reported that overexpression of rice DHAR1 in Arabidopsis increases ascorbate levels, which leads to increased salt tolerance. 
Compatible solute

Severe osmotic stress induced by drought, high salinity, and low temperature disrupts normal cellular activities [181]. Physiological studies have shown that a group of soluble organic compounds accumulate and function as osmoprotectants during osmotic stress [11]. Accumulation of compatible solutes such as amino acids (e.g., proline), quaternary and other amines (e.g., glycine betaine and polyamines), sugars (e.g., raffinose, sucrose, and trehalose), and sugar alcohols (e.g., mannitol) decrease the osmotic potential in the cytoplasm, thus protecting cellular function or maintaining the structure of cellular components [152].

In rice, physiological responses to the accumulation of several compatible solutes, as well as the transcript level of genes encoding enzymes for their synthesis, have been investigated under stress conditions [20, 21, 43, 66, 91, 130]. Manipulation of genes in the metabolic pathways is a common strategy to increase plant stress tolerance. For example, improved tolerance has been found in transgenic rice plants harboring genes involved in metabolism of compatible solutes such as proline [162, 190], glycine betaine [118, 147, 157, 163], polyamines [17, 141, 140], and trehalose $[45,46,74]$.

Modulating multiple steps in the same pathway can result in a more efficient strategy. In Escherichia coli, trehalose-6-phosphate synthase (TPS, encoded by OstA) synthesizes trehalose-6-phosphate from glucose-6phosphate and UDP-glucose. Trehalose-6-phosphate phosphatase (TPP, encoded by $O s t B$ ) then catalyzes the formation of trehalose by removing the phosphate from trehalose-6-phosphate. Overexpression of a bifunctional fusion gene of TPS and TPP from $E$. coli in rice increases the trehalose level and stress tolerance without growth inhibition, probably resulting from reducing levels of deleterious trehalose-6-phosphate [74].

\section{Sodium transporters}

Sodium is a micronutrient in plant cells. Under high salinity, excessive accumulation of $\mathrm{Na}^{+}$in cytosol disrupts enzymatic and photosynthetic functions and causes ion toxicity. Both $\mathrm{Na}^{+}$efflux and vacuolar sequestration contribute to a lower cytosolic $\mathrm{Na}^{+}$concentration. $\mathrm{Na}^{+} / \mathrm{H}^{+}$ antiporters catalyze the exchange of $\mathrm{Na}^{+}$for $\mathrm{H}^{+}$across the membranes in order to maintain ion homeostasis, as well as cytoplasmic $\mathrm{pH}$ and cell turgor [56]. In Arabidopsis, extruding $\mathrm{Na}^{+}$out of cell is mediated by the plasma membrane $\mathrm{Na}^{+} / \mathrm{H}^{+}$antiporter SOS1 [154], whose activity is regulated by the SOS3-SOS2 complex in roots and by the CBL10-SOS2 complex in shoots [132, 133]. Biochemical and genetic analyses have demonstrated that OsSOS1 is a functional homolog of SOS1. Plasma membrane preparations from yeast expressing OsSOS1 show

Table 1 Effect of Selected Rice Genes on Abiotic Stress Tolerance

\begin{tabular}{lll}
\hline Gene (Product) & Phenotype (approach) & Reference \\
\hline Component of signal transduction pathway & & \\
OsCIPK3 (calcineurin B-like-interacting protein kinase) & Cold tolerance (o) & Drought tolerance (o) \\
OsCIPK12 (calcineurin B-like-interacting protein kinase) & Salt tolerance (o) & Cold, drought and salt tolerance (o) \\
OsCIPK15 (calcineurin B-like-interacting protein kinase) & Cold tolerance (o) \\
OsCDPK7 $\left(\mathrm{Ca}^{2+}\right.$-dependent protein kinase) & Cold, drought and salt tolerance (o); \\
OsCDPK13 $\left(\mathrm{Ca}^{2+}\right.$-dependent protein kinase) & Cold, drought and salt sensitivity (r) \\
OsMAP1/OsMAPK5 (mitogen-activated protein kinase) & \\
& Cold, drought and salt tolerance (o) \\
Transcription factor & Salt tolerance (a); Salt sensitivity (o) \\
OsDREB1A, OsDREB1B (DRE-binding protein) & Drought and salt tolerance (o) \\
OsABI5 (bZIP transcription factor) & Cold and salt tolerance (o) \\
SNAC1 (stress-responsive NAC 1) & Submergence tolerance (n, o) \\
SNAC2 (stress-responsive NAC 2) & \\
Sub1A-1 (ethylene-response-factor) & Salt tolerance (o) \\
Functional protein & Salt tolerance (o) \\
OsAPX1, OsAPX2 (ascorbate peroxides) & Cold and salt tolerance (o) \\
DHAR1 (rice dehydroascorbate reductase) & Salt tolerance (o) \\
OsTPP1 (trehalose-6-phosphate phosphatase) & Salt tolerance (o) \\
OsSOS1 (plasma membrane Na $/ \mathrm{H}^{+}$antiporter) & Salt tolerance (n, o) \\
OSNHX1 (tonoplast Na ${ }^{+} \mathrm{H}^{+}$antiporter) & {$[182]$} \\
SKC1 (rice HKT-type Na ${ }^{+}$transporter) & {$[31,70]$} \\
\hline
\end{tabular}

$a$ anti-sense expression, $n$ near-isogenic line, $o$ overexpression, $r$ RNA interference 
greater capacity for $\mathrm{Na}^{+} / \mathrm{H}^{+}$exchange, and OsSOS1 confers salt tolerance to the yeast mutant AXT3K (Denal-4 $\Delta$ nhal $\Delta n h x 1)$ and the Arabidopsis sos1 mutant [112]. $\mathrm{Na}^{+}$in cytosol can also be sequestered into vacuoles by the $\mathrm{Na}^{+} / \mathrm{H}^{+}$antiporter OsNHX1 located in the tonoplast [41, 40]. The overexpression of OsNHX1 improves salt tolerance in transgenic rice plants, without adversely affecting $\mathrm{Na}^{+}$and $\mathrm{K}^{+}$levels or plant growth [41].

A high $\mathrm{K}^{+} / \mathrm{Na}^{+}$ratio is essential for normal cellular functions. There is growing evidence that supports the idea that the capacity of plants to maintain a high $\mathrm{K}^{+} / \mathrm{Na}^{+}$ratio correlates with salt tolerance [108]. Identification of a major quantitative trait locus (QTL) for shoot $\mathrm{K}^{+}$content and salt tolerance revealed that SKCl encodes a HKT-type $\mathrm{Na}^{+}$selective transporter, OsHKT8 or OsHKT1;5 according to the new nomenclature [99, 131, 137]. SKC1 is preferentially expressed in parenchyma cells surrounding xylem vessels and up-regulated by salinity in roots. SKC1 functions to recirculate $\mathrm{Na}^{+}$back to the roots by unloading $\mathrm{Na}^{+}$from xylem sap, thereby maintaining shoot $\mathrm{K}^{+}$homeostasis and enhancing salt tolerance [137]. In Arabidopsis, SOS1 [155] and AtHKT1;1 (or AtHKT1) [13, 164] also reduce shoot $\mathrm{Na}^{+}$concentration through the vascular system, although the mechanisms are different from SKC1 [42].

High-affinity $\mathrm{Na}^{+}$uptake has been reported in $\mathrm{K}^{+}$starved seedlings of wheat [93], rice [44], and barley [53]. However, there is no direct evidence that a channel/ transporter functions in $\mathrm{Na}^{+}$-selective uptake in plant roots. Studies using oshkt2;1 null mutants demonstrated that OsHKT2;1 (or OsHKT1) takes up $\mathrm{Na}^{+}$under $\mathrm{K}^{+}$-starvation conditions [57]. Due to a dramatically reduced influx of $\mathrm{Na}^{+}$in roots, oshkt2;1 mutants accumulate less $\mathrm{Na}^{+}$in roots and shoots. They exhibit growth inhibition only under $\mathrm{K}^{+}$starvation and low- $\mathrm{Na}^{+}$conditions [57]. Unlike Arabidopsis containing one $H K T$ gene, seven $H K T$ genes have been identified in rice cv. Nipponbare [44]. Given this large number of genes, rice may be a better model for understanding the role of HKTs in regulating $\mathrm{Na}^{+}$transport [142].

\section{Perspective}

Abiotic stress is one of the primary factors limiting global crop yields. Genetic and molecular approaches are powerful tools in the identification of a multitude of genes involved in abiotic stress response and tolerance. Combining these approaches with high throughput technologies, such as microarray/genechip, allows for the identification of novel, stress-responsive genes and signaling cross-talk on a genome-wide basis. Moreover, the accessibility of the rice genome and various mutant libraries should accelerate the identification of regulatory components and functional proteins in this crop.
Although substantial progress has been made, breeding and genetic modulation of rice plants in order to improve abiotic stress tolerance is still a challenge. One major limitation to progress is the lack of knowledge of the functions and interactions of tolerance-related genes. While many genes have been identified with great potential for abiotic-stress engineering, most of them, more or less, affect rice morphology when they are constitutively overexpressed. Utilization of some of these genetic characteristics, therefore, while producing desirable stress-related results, may have concomitant negative impacts. Quantifying the advantages and disadvantages of breeding may take some time. However, it is desirable to generate plants with gene expression driven by a controllable promoter so that the gene products are not produced unless under stress conditions. So far, some reports that used a stress-inducible promoter to express foreign genes have shown increased abiotic stress tolerance with normal plant growth [140, $141,162,163]$. Combined with other genetic and molecular approaches, the exploitation of rice stress-responsive genes (Table 1) for engineering breeding will certainly accelerate.

In addition, abiotic stress tolerance is a quantitative trait loci characteristic, influenced by a large number of genes; modulation of one or several genes is limited with regard to favorable abiotic-stress engineering. In the last few decades, QTL mapping studies allowed, at least in part, identification of specific chromosome segments that carry these QTLs or candidate genes. As QTL mapping is a challenging task, only two major QTLs for stress tolerance, SKC1 and Sub1, have been successfully cloned by now. Because a number of minor QTLs may also be responsible for a large portion of phenotypic variation, these minor QTLs can be integrated together with the major QTL by a QTL-pyramiding breeding strategy. QTL pyramiding can assemble tolerant genes together for one specific trait or for two or more different traits by using marker-assisted selection. More knowledge about the genetics and molecular basis of related traits will be helpful in this direction. In conjunction with these efforts, characterization of the genetic and functional interactions of more abiotic stressrelated genes is necessary.

\section{Reference}

1. Abbasi F, Onodera H, Toki S, Tanaka H, Komatsu S. OsCDPK13, a calcium-dependent protein kinase gene from rice, is induced by cold and gibberellin in rice leaf sheath. Plant Mol Biol 2004;55:541-52.

2. Abe H, Yamaguchi-Shinozaki K, Urao T, Iwasaki T, Hosokawa D, Shinozaki K. Role of arabidopsis MYC and MYB homologs in drought- and abscisic acid-regulated gene expression. Plant Cell 1997;9:1859-68. 
3. Abe H, Urao T, Ito T, Seki M, Shinozaki K, YamaguchiShinozaki K. Arabidopsis AtMYC2 (bHLH) and AtMYB2 (MYB) function as transcriptional activators in abscisic acid signaling. Plant Cell 2003;15:63-78.

4. Agrawal GK, Rakwal R, Iwahashi H. Isolation of novel rice (Oryza sativa L.) multiple stress responsive MAP kinase gene, OsMSRMK2, whose mRNA accumulates rapidly in response to environmental cues. Biochem Biophys Res Commun 2002;294:1009-16.

5. Agrawal GK, Iwahashi H, Rakwal R. Rice MAPKs. Biochem Biophys Res Commun 2003;302:171-80.

6. Aguilar PS, Hernandez-Arriaga AM, Cybulski LE, Erazo AC, de Mendoza D. Molecular basis of thermosensing: a two-component signal transduction thermometer in Bacillus subtilis. EMBO J 2001;20:1681-91.

7. Apel K, Hirt H. Reactive oxygen species: metabolism, oxidative stress, and signal transduction. Annu Rev Plant Biol 2004;55:373-99.

8. Asai T, Tena G, Plotnikova J, Willmann MR, Chiu WL, GomezGomez L, et al. MAP kinase signalling cascade in Arabidopsis innate immunity. Nature 2002;415:977-83.

9. Asano T, Tanaka N, Yang G, Hayashi N, Komatsu S. Genomewide identification of the rice calcium-dependent protein kinase and its closely related kinase gene families: comprehensive analysis of the CDPKs gene family in rice. Plant Cell Physiol 2005;46:356-66.

10. Asano T, Kunieda N, Omura Y, Ibe H, Kawasaki T, Takano M, et al. Rice SPK, a calmodulin-like domain protein kinase, is required for storage product accumulation during seed development: phosphorylation of sucrose synthase is a possible factor. Plant Cell 2002;14:619-28.

11. Bartels D, Sunkar R. Drought and salt tolerance in plants. Crit Rev Plant Sci 2005;24:23-58.

12. Berberich T, Kusano T. Cycloheximide induces a subset of low temperature-inducible genes in maize. Mol Gen Genet 1997;254:275-83.

13. Berthomieu P, Conejero G, Nublat A, Brackenbury WJ, Lambert C, Savio C, et al. Functional analysis of AtHKT1 in Arabidopsis shows that $\mathrm{Na}^{+}$recirculation by the phloem is crucial for salt tolerance. EMBO J 2003;22:2004-14.

14. Besant PG, Tan E, Attwood PV. Mammalian protein histidine kinases. Int J Biochem Cell Biol 2003;35:297-309.

15. Boudsocq M, Barbier-Brygoo H, Lauriere C. Identification of nine sucrose nonfermenting 1-related protein kinases 2 activated by hyperosmotic and saline stresses in Arabidopsis thaliana. J Biol Chem 2004;279:41758-66.

16. Breviario D, Morello L, Giani S. Molecular cloning of two novel rice cDNA sequences encoding putative calcium-dependent protein kinases. Plant Mol Biol 1995;27:953-67.

17. Capell T, Bassie L, Christou P. Modulation of the polyamine biosynthetic pathway in transgenic rice confers tolerance to drought stress. Proc Natl Acad Sci USA 2004;101:9909-14.

18. Chae MJ, Lee JS, Nam MH, Cho K, Hong JY, Yi SA, et al. A rice dehydration-inducible SNF1-related protein kinase 2 phosphorylates an abscisic acid responsive element-binding factor and associates with ABA signaling. Plant Mol Biol 2007;63:151-69.

19. Chao DY, Luo YH, Shi M, Luo D, Lin HX. Salt-responsive genes in rice revealed by cDNA microarray analysis. Cell Res 2005; 15:796-810.

20. Chattopadhayay MK, Tiwari BS, Chattopadhyay G, Bose A, Sengupta DN, Ghosh B. Protective role of exogenous polyamines on salinity-stressed rice (Oryza sativa) plants. Physiol Plant 2002;116:192-9.

21. Chattopadhyay MK, Gupta S, Sengupta DN, Ghosh B. Expression of arginine decarboxylase in seedlings of indica rice (Oryza sativa L.) cultivars as affected by salinity stress. Plant Mol Biol 1997;34:477-83.

22. Chen W, Provart NJ, Glazebrook J, Katagiri F, Chang HS, Eulgem $\mathrm{T}$, et al. Expression profile matrix of Arabidopsis transcription factor genes suggests their putative functions in response to environmental stresses. Plant Cell 2002;14:559-74.

23. Cheng SH, Willmann MR, Chen HC, Sheen J. Calcium signaling through protein kinases. The Arabidopsis calcium-dependent protein kinase gene family. Plant Physiol 2002;129:469-85.

24. Chinnusamy V, Jagendorf A, Zhu J-K. Understanding and improving salt tolerance in plants. Crop Sci 2005;45:437-48.

25. Chinnusamy V, Zhu J, Zhu JK. Salt stress signaling and mechanisms of plant salt tolerance. Genet Eng (N Y) 2006;27:141-77.

26. Chinnusamy V, Zhu J, Zhu JK. Gene regulation during cold acclimation in plants. Physiol Plant 2006;126:52-61.

27. Chinnusamy V, Ohta $\mathrm{M}$, Kanrar S, Lee BH, Hong $\mathrm{X}$, Agarwal $M$, et al. ICE1: a regulator of cold-induced transcriptome and freezing tolerance in Arabidopsis. Genes Dev 2003; 17:1043-54.

28. Doi K, Izawa T, Fuse T, Yamanouchi U, Kubo T, Shimatani Z, et al. Ehd1, a B-type response regulator in rice, confers short-day promotion of flowering and controls FT-like gene expression independently of Hd1. Genes Dev 2004;18:926-36.

29. Dong CH, Agarwal M, Zhang Y, Xie Q, Zhu JK. The negative regulator of plant cold responses, HOS1, is a RING E3 ligase that mediates the ubiquitination and degradation of ICE1. Proc Natl Acad Sci USA 2006;103:8281-6.

30. Du L, Jiao F, Chu J, Jin G, Chen M, Wu P. The two-component signal system in rice (Oryza sativa L.): a genome-wide study of cytokinin signal perception and transduction. Genomics 2007;89:697-707.

31. Dubouzet JG, Sakuma Y, Ito Y, Kasuga M, Dubouzet EG, Miura $\mathrm{S}$, et al. OsDREB genes in rice, Oryza sativa L., encode transcription activators that function in drought-, high-salt- and cold-responsive gene expression. Plant J 2003;33:751-63.

32. Ellard-Ivey M, Hopkins RB, White TJ, Lomax TL. Cloning, expression and $\mathrm{N}$-terminal myristoylation of CpCPK1, a calciumdependent protein kinase from zucchini (Cucurbita pepo L.). Plant Mol Biol 1999;39:199-208.

33. Finkelstein RR, Lynch TJ. The Arabidopsis abscisic acid response gene $\mathrm{ABI} 5$ encodes a basic leucine zipper transcription factor. Plant Cell 2000;12:599-609.

34. Fowler S, Thomashow MF. Arabidopsis transcriptome profiling indicates that multiple regulatory pathways are activated during cold acclimation in addition to the CBF cold response pathway. Plant Cell 2002;14:1675-90.

35. Fu SF, Chou WC, Huang DD, Huang HJ. Transcriptional regulation of a rice mitogen-activated protein kinase gene, OsMAPK4, in response to environmental stresses. Plant Cell Physiol 2002;43:958-63.

36. Fujii H, Verslues PE, Zhu JK. Identification of two protein kinases required for abscisic acid regulation of seed germination, root growth, and gene expression in Arabidopsis. Plant Cell 2007; 19:485-94.

37. Fujita M, Fujita Y, Noutoshi Y, Takahashi F, Narusaka Y, Yamaguchi-Shinozaki K, et al. Crosstalk between abiotic and biotic stress responses: a current view from the points of convergence in the stress signaling networks. Curr Opin Plant Biol 2006;9:436-42.

38. Fujita Y, Fujita M, Satoh R, Maruyama K, Parvez MM, Seki $\mathrm{M}$, et al. AREB1 is a transcription activator of novel ABREdependent ABA signaling that enhances drought stress tolerance in Arabidopsis. Plant Cell 2005;17:3470-88.

39. Fukao T, Xu K, Ronald PC, Bailey-Serres J. A variable cluster of ethylene response factor-like genes regulates metabolic and 
developmental acclimation responses to submergence in rice. Plant Cell 2006;18:2021-34.

40. Fukuda A, Nakamura A, Tanaka Y. Molecular cloning and expression of the $\mathrm{Na}^{+} / \mathrm{H}^{+}$exchanger gene in Oryza sativa. Biochim Biophys Acta 1999;1446:149-55.

41. Fukuda A, Nakamura A, Tagiri A, Tanaka H, Miyao A, Hirochika H, Tanaka Y. Function, intracellular localization and the importance in salt tolerance of a vacuolar $\mathrm{Na}^{+} / \mathrm{H}^{+}$antiporter from rice. Plant Cell Physiol 2004;45:146-59.

42. Gao JP, Chao DY, Lin HX. Understanding abiotic stress tolerance mechanisms: Recent studies on stress response in rice. J Integr Plant Biol 2007;49:742-50.

43. Garcia AB, Engler J, Iyer S, Gerats T, Van Montagu M, Caplan $\mathrm{AB}$. Effects of osmoprotectants upon $\mathrm{NaCl}$ stress in rice. Plant Physiol 1997;115:159-69.

44. Garciadeblas B, Senn ME, Banuelos MA, Rodriguez-Navarro A. Sodium transport and HKT transporters: the rice model. Plant J 2003;34:788-801.

45. Garg AK, Kim JK, Owens TG, Ranwala AP, Choi YD, Kochian $\mathrm{LV}$, et al. Trehalose accumulation in rice plants confers high tolerance levels to different abiotic stresses. Proc Natl Acad Sci USA 2002;99:15898-903.

46. Ge LF, Chao DY, Shi M, Zhu MZ, Gao JP, Lin HX. Overexpression of the trehalose-6-phosphate phosphatase gene OsTPP1 confers stress tolerance in rice and results in the activation of stress responsive genes. Planta 2008;228:191-201.

47. Gilroy S, Bethke PC, Jones RL. Calcium homeostasis in plants. J Cell Sci 1993;106(Pt 2):453-61.

48. Guo Y, Halfter U, Ishitani M, Zhu JK. Molecular characterization of functional domains in the protein kinase SOS2 that is required for plant salt tolerance. Plant Cell 2001;13:1383-99.

49. Guo Z, Tan H, Zhu Z, Lu S, Zhou B. Effect of intermediates on ascorbic acid and oxalate biosynthesis of rice and in relation to its stress resistance. Plant Physiol Biochem 2005;43: 955-62.

50. Haake V, Cook D, Riechmann JL, Pineda O, Thomashow MF, Zhang JZ. Transcription factor CBF4 is a regulator of drought adaptation in Arabidopsis. Plant Physiol 2002;130:639-48.

51. Halfter U, Ishitani M, Zhu JK. The Arabidopsis SOS2 protein kinase physically interacts with and is activated by the calciumbinding protein SOS3. Proc Natl Acad Sci USA 2000;97:373540.

52. Harmon AC, Gribskov M, Harper JF. CDPKs - a kinase for every $\mathrm{Ca}^{2+}$ signal? Trends Plant Sci 2000;5:154-9.

53. Haro R, Banuelos MA, Senn ME, Barrero-Gil J, RodriguezNavarro A. HKT1 mediates sodium uniport in roots. Pitfalls in the expression of HKT1 in yeast. Plant Physiol 2005;139:1495506.

54. Higuchi M, Pischke MS, Mahonen AP, Miyawaki K, Hashimoto Y, Seki M, et al. In planta functions of the Arabidopsis cytokinin receptor family. Proc Natl Acad Sci USA 2004;101:8821-6.

55. Hong CY, Hsu YT, Tsai YC, Kao CH. Expression of ASCORBATE PEROXIDASE 8 in roots of rice (Oryza sativa L.) seedlings in response to NaCl. J Exp Bot 2007;58:3273-83.

56. Horie T, Schroeder JI. Sodium transporters in plants. Diverse genes and physiological functions. Plant Physiol 2004;136: 2457-62.

57. Horie T, Costa A, Kim TH, Han MJ, Horie R, Leung HY, et al. Rice OsHKT2;1 transporter mediates large $\mathrm{Na}^{+}$influx component into $\mathrm{K}^{+}$-starved roots for growth. EMBO J 2007;26: 3003-14.

58. Hrabak EM, Chan CW, Gribskov M, Harper JF, Choi JH, Halford N, et al. The Arabidopsis CDPK-SnRK superfamily of protein kinases. Plant Physiol 2003;132:666-80.
59. Hu H, You J, Fang Y, Zhu X, Qi Z, Xiong L. Characterization of transcription factor gene SNAC2 conferring cold and salt tolerance in rice. Plant Mol Biol 2008;67:169-81.

60. $\mathrm{Hu} \mathrm{H}$, Dai M, Yao J, Xiao B, Li X, Zhang Q, et al. Overexpressing a NAM, ATAF, and CUC (NAC) transcription factor enhances drought resistance and salt tolerance in rice. Proc Natl Acad Sci USA 2006;103:12987-92.

61. Huang HJ, Fu SF, Tai YH, Chou WC, Huang DD. Expression of Oryza sativa MAP kinase gene is developmentally regulated and stress-responsive. Physiol Plant 2002;114:572-80.

62. Huber SC, Huber JL, Liao PC, Gage DA, McMichael RW Jr, Chourey PS, et al. Phosphorylation of serine-15 of maize leaf sucrose synthase. Occurrence in vivo and possible regulatory significance. Plant Physiol 1996;112:793-802.

63. Hwang I, Sheen J. Two-component circuitry in Arabidopsis cytokinin signal transduction. Nature 2001;413:383-9.

64. Hwang YS, Bethke PC, Cheong YH, Chang HS, Zhu T, Jones RL. A gibberellin-regulated calcineurin $B$ in rice localizes to the tonoplast and is implicated in vacuole function. Plant Physiol 2005; $138: 1347-58$

65. Ichimura K, Mizoguchi T, Irie K, Morris P, Giraudat J, Matsumoto $\mathrm{K}$, et al. Isolation of ATMEKK1 (a MAP kinase kinase kinase)-interacting proteins and analysis of a MAP kinase cascade in Arabidopsis. Biochem Biophys Res Commun 1998;253:532-43.

66. Igarashi Y, Yoshiba Y, Sanada Y, Yamaguchi-Shinozaki K, Wada $\mathrm{K}$, Shinozaki K. Characterization of the gene for $\Delta^{1}$-pyrroline-5carboxylate synthetase and correlation between the expression of the gene and salt tolerance in Oryza sativa L. Plant Mol Biol 1997;33:857-65.

67. Imamura A, Hanaki N, Nakamura A, Suzuki T, Taniguchi M, Kiba T, et al. Compilation and characterization of Arabidopsis thaliana response regulators implicated in His-Asp phosphorelay signal transduction. Plant Cell Physiol 1999;40:733-42.

68. Imamura A, Yoshino Y, Mizuno T. Cellular localization of the signaling components of Arabidopsis His-to-Asp phosphorelay. Biosci Biotechnol Biochem 2001;65:2113-7.

69. Ishitani M, Liu J, Halfter U, Kim CS, Shi W, Zhu JK. SOS3 function in plant salt tolerance requires $\mathrm{N}$-myristoylation and calcium binding. Plant Cell 2000;12:1667-78.

70. Ito Y, Katsura K, Maruyama K, Taji T, Kobayashi M, Seki M, et al. Functional analysis of rice DREB1/CBF-type transcription factors involved in cold-responsive gene expression in transgenic rice. Plant Cell Physiol 2006;47:141-53.

71. Ito Y, Kurata N. Identification and characterization of cytokininsignalling gene families in rice. Gene 2006;382:57-65.

72. Jaglo-Ottosen KR, Gilmour SJ, Zarka DG, Schabenberger O, Thomashow MF. Arabidopsis CBF1 overexpression induces COR genes and enhances freezing tolerance. Science 1998;280:104-6.

73. Jain M, Tyagi AK, Khurana JP. Molecular characterization and differential expression of cytokinin-responsive type-A response regulators in rice (Oryza sativa). BMC Plant Biol 2006;6:1.

74. Jang IC, Oh SJ, Seo JS, Choi WB, Song SI, Kim CH, et al. Expression of a bifunctional fusion of the Escherichia coli genes for trehalose-6-phosphate synthase and trehalose-6-phosphate phosphatase in transgenic rice plants increases trehalose accumulation and abiotic stress tolerance without stunting growth. Plant Physiol 2003;131:516-24.

75. Jonak C, Okresz L, Bogre L, Hirt H. Complexity, cross talk and integration of plant MAP kinase signalling. Curr Opin Plant Biol 2002;5:415-24.

76. Kang SG, Jeong HK, Suh HS. Characterization of a new member of the glutathione peroxidase gene family in Oryza sativa. Mol Cells 2004;17:23-8. 
77. Katou S, Kuroda K, Seo S, Yanagawa Y, Tsuge T, Yamazaki $\mathrm{M}$, et al. A calmodulin-binding mitogen-activated protein kinase phosphatase is induced by wounding and regulates the activities of stress-related mitogen-activated protein kinases in rice. Plant Cell Physiol 2007;48:332-44.

78. Kawasaki T, Hayashida N, Baba T, Shinozaki K, Shimada H. The gene encoding a calcium-dependent protein kinase located near the sbel gene encoding starch branching enzyme I is specifically expressed in developing rice seeds. Gene 1993;129:183-9.

79. Keyse SM. Protein phosphatases and the regulation of mitogenactivated protein kinase signalling. Curr Opin Cell Biol 2000;12: 186-92.

80. Kiba T, Yamada H, Sato S, Kato T, Tabata S, Yamashino T, et al. The type-A response regulator, ARR15, acts as a negative regulator in the cytokinin-mediated signal transduction in Arabidopsis thaliana. Plant Cell Physiol 2003;44:868-74.

81. Kim JA, Agrawal GK, Rakwal R, Han KS, Kim KN, Yun CH, et al. Molecular cloning and mRNA expression analysis of a novel rice (Oryza sativa L.) MAPK kinase kinase, OsEDR1, an ortholog of Arabidopsis AtEDR1, reveal its role in defense/ stress signalling pathways and development. Biochem Biophys Res Commun 2003;300:868-76.

82. Kim K-N, Lee J-S, Han H, Ah Choi S, Joo Go S, Sun Yoon I. Isolation and characterization of a novel rice $\mathrm{Ca}^{2+}$-regulated protein kinase gene involved in responses to diverse signals including cold, light, cytokinins, sugars and salts. Plant Mol Biol 2003;52:1191-202.

83. Kiyosue T, Yamaguchi-Shinozaki K, Shinozaki K. Characterization of cDNA for a dehydration-inducible gene that encodes a CLP A, B-like protein in Arabidopsis thaliana L. Biochem Biophys Res Commun 1993;196:1214-20.

84. Knight H. Calcium signaling during abiotic stress in plants. Int Rev Cytol 2000;195:269-324.

85. Knight H, Knight MR. Abiotic stress signalling pathways: specificity and cross-talk. Trends Plant Sci 2001;6:262-7.

86. Kobayashi Y, Murata M, Minami H, Yamamoto S, Kagaya Y, Hobo $\mathrm{T}$, et al. Abscisic acid-activated SNRK2 protein kinases function in the gene-regulation pathway of ABA signal transduction by phosphorylating ABA response element-binding factors. Plant J 2005;44:939-49.

87. Kobayashi Y, Yamamoto S, Minami H, Kagaya Y, Hattori T. Differential activation of the rice sucrose nonfermenting1-related protein kinase 2 family by hyperosmotic stress and abscisic acid. Plant Cell 2004;16:1163-77.

88. Kolukisaoglu U, Weinl S, Blazevic D, Batistic O, Kudla J. Calcium sensors and their interacting protein kinases: genomics of the Arabidopsis and rice CBL-CIPK signaling networks. Plant Physiol 2004; 134:43-58.

89. Kovtun Y, Chiu WL, Tena G, Sheen J. Functional analysis of oxidative stress-activated mitogen-activated protein kinase cascade in plants. Proc Natl Acad Sci USA 2000;97:2940-5.

90. Kreps JA, Wu Y, Chang HS, Zhu T, Wang X, Harper JF. Transcriptome changes for Arabidopsis in response to salt, osmotic, and cold stress. Plant Physiol 2002;130:2129-41.

91. Krishnamurthy R, Bhagwat KA. Polyamines as modulators of salt tolerance in rice cultivars. Plant Physiol 1989;91:500-4.

92. Lafitte HR, Ismail A, Bennett J. Abiotic stress tolerance in rice for Asia: progress and the future. New Directions for a Diverse Planet 2004. Proceedings for the 4th International Crop Science Congress, Brisbane, Australia, 26 September-1 October 2004. The Regional Institute Ltd. http://www.cropscience.org.au/ icsc2004.

93. Laurie S, Feeney KA, Maathuis FJ, Heard PJ, Brown SJ, Leigh RA. A role for HKT1 in sodium uptake by wheat roots. Plant J 2002;32:139-49.
94. Lee BH, Henderson DA, Zhu JK. The Arabidopsis coldresponsive transcriptome and its regulation by ICE1. Plant Cell 2005;17:3155-75.

95. Leonhardt N, Kwak JM, Robert N, Waner D, Leonhardt G, Schroeder JI. Microarray expression analyses of Arabidopsis guard cells and isolation of a recessive abscisic acid hypersensitive protein phosphatase 2C mutant. Plant Cell 2004;16:596-615.

96. Li L, Kim BG, Cheong YH, Pandey GK, Luan S. A Ca ${ }^{2+}$ signaling pathway regulates a $\mathrm{K}^{+}$channel for low-K response in Arabidopsis. Proc Natl Acad Sci USA 2006;103:12625-30.

97. Li WJ, Feng H, Fan JH, Zhang RQ, Zhao NM, Liu JY. Molecular cloning and expression of a phospholipid hydroperoxide glutathione peroxidase homolog in Oryza sativa. Biochim Biophys Acta 2000;1493:225-30.

98. Lin CW, Chang HB, Huang HJ. Zinc induces mitogen-activated protein kinase activation mediated by reactive oxygen species in rice roots. Plant Physiol Biochem 2005;43:963-8.

99. Lin HX, Zhu MZ, Yano M, Gao JP, Liang ZW, Su WA, et al. QTLs for $\mathrm{Na}^{+}$and $\mathrm{K}^{+}$uptake of the shoots and roots controlling rice salt tolerance. Theor Appl Genet 2004;108:253-60.

100. Liu J, Zhu JK. A calcium sensor homolog required for plant salt tolerance. Science 1998;280:1943-5.

101. Liu J, Ishitani M, Halfter U, Kim CS, Zhu JK. The Arabidopsis thaliana SOS2 gene encodes a protein kinase that is required for salt tolerance. Proc Natl Acad Sci USA 2000;97:3730-4.

102. Liu Q, Kasuga M, Sakuma Y, Abe H, Miura S, YamaguchiShinozaki K, et al. Two transcription factors, DREB1 and DREB2, with an EREBP/AP2 DNA binding domain separate two cellular signal transduction pathways in drought- and low-temperature-responsive gene expression, respectively, in Arabidopsis. Plant Cell 1998;10:1391-406.

103. Liu X, Yue Y, Li B, Nie Y, Li W, Wu W-H, et al. A G proteincoupled receptor is a plasma membrane receptor for the plant hormone abscisic acid. Science 2007;315:1712-6.

104. Lu Z, Liu D, Liu S. Two rice cytosolic ascorbate peroxidases differentially improve salt tolerance in transgenic Arabidopsis. Plant Cell Rep 2007;26:1909-17.

105. Luan S, Kudla J, Rodriguez-Concepcion M, Yalovsky S, Gruissem W. Calmodulins and calcineurin B-like proteins: calcium sensors for specific signal response coupling in plants. Plant Cell 2002;14(Suppl):S389-400.

106. Ludwig AA, Romeis T, Jones JD. CDPK-mediated signalling pathways: specificity and cross-talk. J Exp Bot 2004;55:181-8.

107. Ma X, Qian Q, Zhu D. Expression of a calcineurin gene improves salt stress tolerance in transgenic rice. Plant Mol Biol 2005;58:483-95.

108. Maathuis FJM, Amtmann A. $\mathrm{K}^{+}$nutrition and $\mathrm{Na}^{+}$toxicity: the basis of cellular $\mathrm{K}^{+} / \mathrm{Na}^{+}$ratios. Ann Bot 1999;84:123-33.

109. Maclean JL, Dawe DC, Hardy B, Hettel GP. Rice almanac. 3rd ed. Los Baños, Philippines: International Rice Research Institute; Bouaké, Côte d'Ivoire: West Africa Rice Development Association; Cali, Colombia: International Center for Tropical Agriculture; Rome, Italy: Food and Agriculture Organization; 2002.

110. Maeda T, Wurgler-Murphy SM, Saito H. A two-component system that regulates an osmosensing MAP kinase cascade in yeast. Nature 1994;369:242-5.

111. MAPK Group. Mitogen-activated protein kinase cascades in plants: a new nomenclature, Trends Plant Sci 2002;7:301-8.

112. Martinez-Atienza J, Jiang X, Garciadeblas B, Mendoza I, Zhu JK, Pardo J, et al. Conservation of the salt overly sensitive pathway in rice. Plant Physiol 2007;143:1001-12.

113. Mendoza I, Rubio F, Rodriguez-Navarro A, Pardo JM. The protein phosphatase calcineurin is essential for $\mathrm{NaCl}$ tolerance of Saccharomyces cerevisiae. J Biol Chem 1994;269:8792-6. 
114. Mittler R. Oxidative stress, antioxidants and stress tolerance. Trends Plant Sci 2002; 7:405-10.

115. Miura K, Jin JB, Lee J, Yoo CY, Stirm V, Miura T, et al. SIZ1mediated sumoylation of ICE1 controls CBF3/DREB1A expression and freezing tolerance in Arabidopsis. Plant Cell 2007;19: 1403-14.

116. Mizoguchi T, Irie K, Hirayama T, Hayashida N, YamaguchiShinozaki K, Matsumoto $\mathrm{K}$, et al. A gene encoding a mitogen-activated protein kinase kinase kinase is induced simultaneously with genes for a mitogen-activated protein kinase and an S6 ribosomal protein kinase by touch, cold, and water stress in Arabidopsis thaliana. Proc Natl Acad Sci USA 1996;93:765-9.

117. Mizoguchi T, Ichimura K, Irie K, Morris $P$, Giraudat $J$, Matsumoto $\mathrm{K}$, et al. Identification of a possible MAP kinase cascade in Arabidopsis thaliana based on pairwise yeast twohybrid analysis and functional complementation tests of yeast mutants. FEBS Lett 1998;437:56-60.

118. Mohanty A, Kathuria H, Ferjani A, Sakamoto A, Mohanty P, Murata N, et al. Transgenics of an elite indica rice variety Pusa Basmati 1 harbouring the codA gene are highly tolerant to salt stress. Theor Appl Genet 2002;106:51-7.

119. Nakamura T, Liu Y, Hirata D, Namba H, Harada S, Hirokawa T, et al. Protein phosphatase type 2B (calcineurin)-mediated, FK506-sensitive regulation of intracellular ions in yeast is an important determinant for adaptation to high salt stress conditions. EMBO J 1993;12:4063-71.

120. Nakashima K, Kiyosue T, Yamaguchi-Shinozaki K, Shinozaki K. A nuclear gene, erd1, encoding a chloroplast-targeted Clp protease regulatory subunit homolog is not only induced by water stress but also developmentally up-regulated during senescence in Arabidopsis thaliana. Plant J 1997;12:851-61.

121. Nakashima K, Tran LS, Van Nguyen D, Fujita M, Maruyama K, Todaka D, et al. Functional analysis of a NAC-type transcription factor OsNAC6 involved in abiotic and biotic stress-responsive gene expression in rice. Plant J 2007;51:617-30.

122. Nishimura C, Ohashi Y, Sato S, Kato T, Tabata S, Ueguchi C. Histidine kinase homologs that act as cytokinin receptors possess overlapping functions in the regulation of shoot and root growth in Arabidopsis. Plant Cell 2004;16:1365-77.

123. Oh SJ, Song SI, Kim YS, Jang HJ, Kim SY, Kim M, et al. Arabidopsis $\mathrm{CBF} 3 / \mathrm{DREB} 1 \mathrm{~A}$ and $\mathrm{ABF} 3$ in transgenic rice increased tolerance to abiotic stress without stunting growth. Plant Physiol 2005;138:341-51.

124. Ohba H, Steward N, Kawasaki S, Berberich T, Ikeda Y, Koizumi $\mathrm{N}$, et al. Diverse response of rice and maize genes encoding homologs of WPK4, an SNF1-related protein kinase from wheat, to light, nutrients, low temperature and cytokinins. Mol Gen Genet 2000;263:359-66.

125. Ohnishi T, Sugahara S, Yamada T, Kikuchi K, Yoshiba Y, Hirano HY, et al. OsNAC6, a member of the NAC gene family, is induced by various stresses in rice. Genes Genet Syst 2005;80: 135-9.

126. Ooka H, Satoh K, Doi K, Nagata T, Otomo Y, Murakami K, et al. Comprehensive analysis of NAC family genes in Oryza sativa and Arabidopsis thaliana. DNA Res 2003;10:239-47.

127. Paithoonrangsarid K, Shoumskaya MA, Kanesaki Y, Satoh S, Tabata S, Los DA, et al. Five histidine kinases perceive osmotic stress and regulate distinct sets of genes in Synechocystis. J Biol Chem 2004;279:53078-86.

128. Pareek A, Singh A, Kumar M, Kushwaha HR, Lynn AM, SinglaPareek SL. Whole-genome analysis of Oryza sativa reveals similar architecture of two-component signaling machinery with Arabidopsis. Plant Physiol 2006;142:380-97.

129. Patharkar OR, Cushman JC. A stress-induced calcium-dependent protein kinase from Mesembryanthemum crystallinum phosphor- ylates a two-component pseudo-response regulator. Plant $\mathrm{J}$ 2000;24:679-91.

130. Pillai MA, Akiyama T. Differential expression of an $S$-adenosylL-methionine decarboxylase gene involved in polyamine biosynthesis under low temperature stress in japonica and indica rice genotypes. Mol Genet Genomics 2004;271:141-9.

131. Platten JD, Cotsaftis O, Berthomieu P, Bohnert H, Davenport RJ, Fairbairn DJ, et al. Nomenclature for HKT transporters, key determinants of plant salinity tolerance. Trends Plant Sci 2006;11:372-4.

132. Qiu QS, Guo Y, Dietrich MA, Schumaker KS, Zhu JK. Regulation of SOS1, a plasma membrane $\mathrm{Na}^{+} / \mathrm{H}^{+}$exchanger in Arabidopsis thaliana, by SOS2 and SOS3. Proc Natl Acad Sci USA 2002;99:8436-41.

133. Quan R, Lin H, Mendoza I, Zhang Y, Cao W, Yang Y, et al. SCABP8/CBL10, a putative calcium sensor, interacts with the protein kinase SOS2 to protect Arabidopsis shoots from salt stress. Plant Cell 2007;19:1415-31.

134. Quintero FJ, Ohta M, Shi H, Zhu JK, Pardo JM. Reconstitution in yeast of the Arabidopsis SOS signaling pathway for $\mathrm{Na}^{+}$ homeostasis. Proc Natl Acad Sci USA 2002;99:9061-6.

135. Ray S, Agarwal P, Arora R, Kapoor S, Tyagi AK. Expression analysis of calcium-dependent protein kinase gene family during reproductive development and abiotic stress conditions in rice (Oryza sativa L. ssp. indica). Mol Genet Genomics 2007;278: 493-505.

136. Razem FA, El-Kereamy A, Abrams SR, Hill RD. The RNAbinding protein FCA is an abscisic acid receptor. Nature 2006;439:290-4.

137. Ren ZH, Gao JP, Li LG, Cai XL, Huang W, Chao DY, et al. A rice quantitative trait locus for salt tolerance encodes a sodium transporter. Nat Genet 2005;37:1141-6.

138. Roberts DM, Harmon AC. Calcium modulated protein: targets of intracellular calcium signals in higher plants. Annu Rev Plant Physiol Plant Mol Biol 1992;43:375-414.

139. Romeis T, Ludwig AA, Martin R, Jones JD. Calcium-dependent protein kinases play an essential role in a plant defence response. EMBO J 2001;20:5556-67.

140. Roy M, Wu R. Arginine decarboxylase transgene expression and analysis of environmental stress tolerance in transgenic rice. Plant Sci 2001;160:869-75.

141. Roy M, Wu R. Overexpression of $S$-adenosylmethionine decarboxylase gene in rice increases polyamine level and enhances sodium chloride-stress tolerance. Plant Sci 2002;163: 987-92.

142. Rus AM, Bressan RA, Hasegawa PM. Unraveling salt tolerance in crops. Nat Genet 2005;37:1029-30.

143. Rusnak F, Mertz P. Calcineurin: form and function. Physiol Rev 2000;80:1483-521.

144. Saijo Y, Hata S, Sheen J, Izui K. cDNA cloning and prokaryotic expression of maize calcium-dependent protein kinases. Biochim Biophys Acta 1997;1350:109-14.

145. Saijo Y, Hata S, Kyozuka J, Shimamoto K, Izui K. Overexpression of a single $\mathrm{Ca}^{2+}$-dependent protein kinase confers both cold and salt/drought tolerance on rice plants. Plant $\mathrm{J}$ 2000;23:319-27.

146. Sakai H, Honma T, Aoyama T, Sato S, Kato T, Tabata S, et al. ARR1, a transcription factor for genes immediately responsive to cytokinins. Science 2001;294:1519-21.

147. Sakamoto A, Murata AN. Metabolic engineering of rice leading to biosynthesis of glycinebetaine and tolerance to salt and cold. Plant Mol Biol 1998;38:1011-9.

148. Sakuma Y, Maruyama K, Osakabe Y, Qin F, Seki M, Shinozaki $\mathrm{K}$, et al. Functional analysis of an Arabidopsis transcription factor, DREB2A, involved in drought-responsive gene expression. Plant Cell 2006;18:1292-309. 
149. Sanchez-Barrena MJ, Martinez-Ripoll M, Zhu JK, Albert A. The structure of the Arabidopsis thaliana SOS3: molecular mechanism of sensing calcium for salt stress response. J Mol Biol 2005;345:1253-64.

150. Sanders D, Brownlee C, Harper JF. Communicating with calcium. Plant Cell 1999;11:691-706.

151. Sanders D, Pelloux J, Brownlee C, Harper JF. Calcium at the crossroads of signaling. Plant Cell 2002;14(Suppl):S401-417.

152. Seki M, Umezawa T, Urano K, Shinozaki K. Regulatory metabolic networks in drought stress responses. Curr Opin Plant Biol 2007;10:296-302.

153. Shen Y-Y, Wang X-F, Wu F-Q, Du S-Y, Cao Z, Shang Y, et al. The Mg-chelatase $\mathrm{H}$ subunit is an abscisic acid receptor. Nature 2006;443:823-6.

154. Shi H, Ishitani M, Kim C, Zhu JK. The Arabidopsis thaliana salt tolerance gene SOS1 encodes a putative $\mathrm{Na}^{+} / \mathrm{H}^{+}$antiporter. Proc Natl Acad Sci USA 2000;97:6896-901.

155. Shi H, Quintero FJ, Pardo JM, Zhu JK. The putative plasma membrane $\mathrm{Na}^{+} / \mathrm{H}^{+}$antiporter SOS1 controls long-distance $\mathrm{Na}^{+}$ transport in plants. Plant Cell 2002;14:465-77.

156. Shinozaki K, Yamaguchi-Shinozaki K. Molecular responses to dehydration and low temperature: differences and cross-talk between two stress signaling pathways. Curr Opin Plant Biol 2000;3:217-23.

157. Shirasawa K, Takabe T, Takabe T, Kishitani S. Accumulation of glycinebetaine in rice plants that overexpress choline monooxygenase from spinach and evaluation of their tolerance to abiotic stress. Ann Bot (Lond) 2006;98:565-71.

158. Simpson SD, Nakashima K, Narusaka Y, Seki M, Shinozaki K, Yamaguchi-Shinozaki K. Two different novel cis-acting elements of erd1, a clpA homologous Arabidopsis gene function in induction by dehydration stress and dark-induced senescence. Plant J 2003;33:259-70.

159. Song F, Goodman RM. OsBIMK1, a rice MAP kinase gene involved in disease resistance responses. Planta 2002;215:9971005 .

160. Stock AM, Robinson VL, Goudreau PN. Two-component signal transduction. Annu Rev Biochem 2000;69:183-215.

161. Stockinger EJ, Gilmour SJ, Thomashow MF. Arabidopsis thaliana CBF1 encodes an AP2 domain-containing transcriptional activator that binds to the C-repeat/DRE, a cis-acting DNA regulatory element that stimulates transcription in response to low temperature and water deficit. Proc Natl Acad Sci USA 1997;94:1035-40.

162. Su J, Wu R. Stress-inducible synthesis of proline in transgenic rice confers faster growth under stress conditions than that with constitutive synthesis. Plant Sci 2004;166:941-8.

163. Su J, Hirji R, Zhang L, He C, Selvaraj G, Wu R. Evaluation of the stress-inducible production of choline oxidase in transgenic rice as a strategy for producing the stress-protectant glycine betaine. J Exp Bot 2006;57:1129-35.

164. Sunarpi HT, Motoda J, Kubo M, Yang H, Yoda K, Horie R, et al. Enhanced salt tolerance mediated by AtHKT1 transporterinduced $\mathrm{Na}^{+}$unloading from xylem vessels to xylem parenchyma cells. Plant J 2005;44:928-38.

165. Sunkar R, Chinnusamy V, Zhu J, Zhu JK. Small RNAs as big players in plant abiotic stress responses and nutrient deprivation. Trends Plant Sci 2007;12:301-9.

166. Suzuki I, Los DA, Kanesaki Y, Mikami K, Murata N. The pathway for perception and transduction of low-temperature signals in Synechocystis. EMBO J 2000;19:1327-34.

167. Teige M, Scheikl E, Eulgem T, Doczi R, Ichimura K, Shinozaki $\mathrm{K}$, et al. The MKK2 pathway mediates cold and salt stress signaling in Arabidopsis. Mol Cell 2004;15:141-52.

168. Teixeira FK, Menezes-Benavente L, Galvao VC, Margis R, Margis-Pinheiro M. Rice ascorbate peroxidase gene family encodes functionally diverse isoforms localized in different subcellular compartments. Planta 2006;224:300-14.

169. Tena G, Asai T, Chiu WL, Sheen J. Plant mitogen-activated protein kinase signaling cascades. Curr Opin Plant Biol 2001;4:392-400.

170. Thomashow MF. Plant cold acclimation: freezing tolerance genes and regulatory mechanisms. Annu Rev Plant Physiol Plant Mol Biol 1999;50:571-99.

171. Tran LS, Urao T, Qin F, Maruyama K, Kakimoto T, Shinozaki K, et al. Functional analysis of AHK1/ATHK1 and cytokinin receptor histidine kinases in response to abscisic acid, drought, and salt stress in Arabidopsis. Proc Natl Acad Sci USA 2007;104:20623-8.

172. Uno Y, Furihata T, Abe H, Yoshida R, Shinozaki K, YamaguchiShinozaki K. Arabidopsis basic leucine zipper transcription factors involved in an abscisic acid-dependent signal transduction pathway under drought and high-salinity conditions. Proc Natl Acad Sci USA 2000;97:11632-7.

173. Urao T, Yamaguchi-Shinozaki K, Shinozaki K. Two-component systems in plant signal transduction. Trends Plant Sci 2000;5:6774.

174. Urao T, Katagiri T, Mizoguchi T, Yamaguchi-Shinozaki K, Hayashida N, Shinozaki K. Two genes that encode $\mathrm{Ca}^{2+}$. dependent protein kinases are induced by drought and high-salt stresses in Arabidopsis thaliana. Mol Gen Genet 1994;244:33140.

175. Urao T, Yakubov B, Satoh R, Yamaguchi-Shinozaki K, Seki M, Hirayama T, et al. A transmembrane hybrid-type histidine kinase in Arabidopsis functions as an osmosensor. Plant Cell 1999;11:1743-54.

176. Ushimaru T, Nakagawa T, Fujioka Y, Daicho K, Naito M, Yamauchi Y, et al. Transgenic Arabidopsis plants expressing the rice dehydroascorbate reductase gene are resistant to salt stress. J Plant Physiol 2006;163:1179-84.

177. Wan B, Lin Y, Mou T. Expression of rice $\mathrm{Ca}^{2+}$-dependent protein kinases (CDPKs) genes under different environmental stresses. FEBS Lett 2007;581:1179-89.

178. Wen JQ, Oono K, Imai R. Two novel mitogen-activated protein signaling components, OsMEK1 and OsMAP1, are involved in a moderate low-temperature signaling pathway in rice. Plant Physiol 2002;129:1880-91.

179. Widmann C, Gibson S, Jarpe MB, Johnson GL. Mitogenactivated protein kinase: conservation of a three-kinase module from yeast to human. Physiol Rev 1999;79:143-80.

180. Xiang Y, Huang Y, Xiong L. Characterization of stressresponsive CIPK genes in rice for stress tolerance improvement. Plant Physiol 2007;144:1416-28.

181. Xiong L, Zhu JK. Molecular and genetic aspects of plant responses to osmotic stress. Plant Cell Environ 2002;25:131-9.

182. Xiong L, Yang Y. Disease resistance and abiotic stress tolerance in rice are inversely modulated by an abscisic acid-inducible mitogen-activated protein kinase. Plant Cell 2003;15:745-59.

183. Xiong L, Schumaker KS, Zhu JK. Cell signaling during cold, drought, and salt stress. Plant Cell 2002;14(Suppl):S165-183.

184. Xu J, Li HD, Chen LQ, Wang Y, Liu LL, He L, et al. A protein kinase, interacting with two calcineurin B-like proteins, regulates $\mathrm{K}^{+}$transporter AKT1 in Arabidopsis. Cell 2006;125:1347-60.

185. Xu K, Xu X, Fukao T, Canlas P, Maghirang-Rodriguez R, Heuer $\mathrm{S}$, et al. Sub1A is an ethylene-response-factor-like gene that confers submergence tolerance to rice. Nature 2006;442:705-8.

186. Yamaguchi-Shinozaki K, Shinozaki K. Organization of cisacting regulatory elements in osmotic- and cold-stress-responsive promoters. Trends Plant Sci 2005;10:88-94.

187. Yeh CM, Hsiao LJ, Huang HJ. Cadmium activates a mitogenactivated protein kinase gene and MBP kinases in rice. Plant Cell Physiol 2004;45:1306-12. 
188. Yeh CM, Chien PS, Huang HJ. Distinct signalling pathways for induction of MAP kinase activities by cadmium and copper in rice roots. J Exp Bot 2007;58:659-71.

189. Zhang XQ, Chollet R. Seryl-phosphorylation of soybean nodule sucrose synthase (nodulin-100) by a $\mathrm{Ca}^{2+}$-dependent protein kinase. FEBS Lett 1997;410:126-30.

190. Zhu BC, Su J, Chang MC, Verma DPS, Fan YL, Wu R. Overexpression of a $\Delta^{1}$-pyrroline-5-carboxylate synthetase gene and analysis of tolerance to water- and salt-stress in transgenic rice. Plant Sci 1998;139:41-8.
191. Zhu J, Dong CH, Zhu JK. Interplay between coldresponsive gene regulation, metabolism and RNA processing during plant cold acclimation. Curr Opin Plant Biol 2007;10:290-95.

192. Zhu JK. Plant salt tolerance. Trends Plant Sci 2001;6:66-71.

193. Zhu JK. Salt and drought stress signal transduction in plants. Annu Rev Plant Biol 2002;53:247-73.

194. Zou M, Guan Y, Ren H, Zhang F, Chen F. A bZIP transcription factor, OsABI5, is involved in rice fertility and stress tolerance. Plant Mol Biol 2008;66:675-83. 